\title{
Meaning Discrimination as a Function of Equivalent Relation and Part of Speech: The Case of Hezaareh English-Persian Dictionary
}

\author{
Zohreh Gharaei (Corresponding Author) \\ Department of English, Faculty of Fo reign Languages, University of Isfahan, Isfahan, Iran \\ Ahmad Moinzadeh \\ Depart ment of English, Faculty of Fo reign Languages, University of Isfahan, Isfahan, Iran \\ Hossein Barati \\ Department of English, Faculty of Fo reign Languages, University of Isfahan, Isfahan, Iran
}

\begin{abstract}
To facilitate the task of meaning discrimination on the part of the users, addressing strategies are assigned to translation equivalents in dictionaries. The rate of addressing strategies assigned to different words in a dictionary should not be either at random or in a consistent way. In this study it is believed that the addressing rate (AR) should be affected by such variables as equivalent relation (ER) and part of speech. This article statistically examines the practice of Hezaareh English-Persian dictionary in assigning addressing strategies to different items. The results indicate that there is no systematic relationship between AR and ERs. It is also revealed that items belonging to different parts of speech are not adequately addressed, either. The article proposes that to be communicatively successful the dictionary compilers of Hezaareh should allocate more AR to the items in which the ERs of semantic or poly divergence prevail. Besides, the role verbs play in comprehension related purposes and their polysemous nature make them good candidates for receiving higher ARs.
\end{abstract}

Index Terms - bilingual dictionary, meaning discrimination, equivalent relation, part of speech, addressing rate

\section{INTRODUCTION}

Although one important task of bilingual lexicographers is to provide users with appropriate translation equivalents, preparing a list of equivalents is not sufficient. To maximize the functionality of a bilingual dictionary and to help users make optimum use of the equivalents offered, it is wise to devise some meaning discriminatory strategies to address the translation equivalents (Gouws and Prinsloo, 2005). According to Piotrowski (1994) any method of distinguishing the senses and strings of equivalents in meaning is known as "meaning discrimination". The SW is said to be addressed when one or more methods are employed by the lexicographer to discriminate the meanings of the SW (Gouws, 2002). Depending on the number of meanings each SW has in the TL and the amount of addressing each meaning receives, the addressing rate (AR) of each item varies. While the importance of the implementation of methods and strategies as such for addressing the equivalents might not be debatable, a fundamental issue arises concerning the amount of addressing each word requires. The is sue gains even more prominence in the light of the limitations on dictionary space.

The amount of addressing strategies is advised to be neither at random nor in a consistent way (Gouws, 2002); instead, it is wise to be regarded as a function of the lexicographic "perspective" and "purpose". With regard to the perspective of the dictionary, a distinction should be drawn between active and receptive dictionaries. While an active dictionary is intended for encoding purposes and helping such linguistic activities as writing and speaking, a receptive dictionary is intended for decoding, for activities such as listening and reading. As for the purpose of the dictionary, another distinction can be made between general purpose and special purpose dictionaries. As the terms suggest, a general purpose dictionary is designed for the public and covers as wide a range as possible of the general vocabulary items of the SL, while a special purpose bilingual dictionary is designed to meet the special needs of a certain group of users. It provides the users with technical and scientific terms of the SL in a special field of study. Users, according to their needs, choose a dictionary with a specific perspective and purpose and expect the dictionary to be responsive to their needs. As a result, it is the type of dictionary and its intended users which determine which vocabulary items should be prioritized as far as addressing strategies are concerned.

A receptive general purpose bilingual dictionary which is compiled for non-native English speakers should facilitate comprehension related activities of the wide range of the users it aims at. For a dictionary as such to be successful at the important task of meaning discrimination, a number of questions should be answered in advance: What are the users' 
lookup needs? How do the addressing strategies of the dictionary help the users with their comprehension? On what basis different ARs should be allocated to different entries? What are the most problem inducing vocabulary items as far as meaning discrimination on the part of the users is concerned?

\section{LITERATURE REVIEW}

Al-Kasimi (1983), suggests that bilingual dictionaries should provide meaning discriminations so as to enable a user to select the appropriate equivalent. He further maintains "unless the problem of meaning discrimination is solved systematically, the bilingual dictionary cannot be a dependable guide to the proper equivalents" (p.68). He believes that meaning discrimination depends on whether the dictionary is meant for comprehension or production, and whether it is intended for speakers of a SL or TL. According to him, on occasions when the SL has a concept for which the TL has more than one equivalent and also when the SL item is polysemous and for each sense there is more than one equivalent in the TL and each equivalent is in turn polysemous, meaning discrimination is necessary. Al-Kasimi is of the opinion that proper meaning discrimination can be achieved by using one of the following devices: punctuation, illustrative examples, indicating parts of speech, usage labels and context words or phrases.

Gouws (2002, p.197) stressing the fact that the distribution of data in dictionaries "has to be motivated on functional grounds and not on an attempt to provide an equal data presentation" for all entries, suggests that different types of "equivalent relations" have varying need for entries to support the translation equivalent. He also maintains that the relation of "congruence" holds few problems for the lexicographer, while "divergence" and "surrogate" demand a wellplanned system of addressing. He believes that in the case of "lexical divergence", it is not enough to make the user aware of the fact that the partial TL synonyms can substitute the source language words; the users must be also informed that the target equivalents cannot substitute one another in all occurrences of the SW. With regard to the "semantic divergence", as he believes, lexicographers should not assume that the users know which translation equivalent to choose in a given situation; instead, they should employ meaning discrimination strategies to ensure an optimal retrieval of information on the part of the users. The same argumentation holds true for the cases of "poly divergence". The strategies offered by Gouws are the use of illustrative examples along with glosses and labels and the use of synopsis articles "to allow a stronger encyclopedic approach in the treatment of culturally bound lexical items" (p.202).

Mafela (2004) evaluating the treatment of meaning discrimination in Venda bilingual dictionaries as unsatisfactory, asserts that lexicographers should enhance the possibilities for equivalent discrimination. He further suggests, additional information as such, enables dictionary users to interpret the meaning of utterances in context and adds to the communicative success of the bilingual dictionary. Mafela (2005) indicates that in case of entries each having more than one equivalent, the lack of meaning discrimination strategies impedes the user to choose the most appropriate equivalent.

According to Gouws and Prinsloo (2005) the comment on semantics in bilingual dictionaries should make provision for a treatment procedure that has all the polysemous senses of a lexical item in its scope. Gouws and Prinsloo further believe that "polysemy is a language specific feature which implies that for a polysemous word in the SL one will not necessarily find a TL translation equivalent with exactly the same polys emous senses." (p.151) In such cases, according to them, lexicographers not only have to provide a translation equivalent for each of the polysemous senses of the item, but also have to make sure that a target user of a given dictionary can achieve a successful retrieval of information from the translation equivalent paradigm. This means that for all translation equivalents that are polysemous, each word should be accompanied by extra-linguistic information. This will enable users to discriminate the senses. According to them, "it is of extreme importance that the lexicographic treatment presented in a bilingual dictionary may not leave the translation equivalents isolated from their typical contexts and cotexts." They add "where these supporting entries are not given as part of lexicographic treatment the users are at a loss in their attempts to retrieve information that can lead to a successful use of the target language form.” (p.153) Other scholars of the field such as Svensén (1993), Bullon (1995), Mavoungou (2001) and Mpofu (2001) have all stressed the importance of the incorporation of sense discriminatory strategies in the comment on semantics of bilingual dictionaries.

In spite of the importance given to the wise application of meaning discriminatory strategies in dictionaries in general, and bilingual ones in particular, and despite the widespread use of English-Persian dictionaries, no study could be found to bring the existing frequently used English-Persian dictionaries under closer examination with this regard. The present study, therefore, tries to assess whether Hezaareh, the most frequently used English-Persian dictionary, has a systematic treatment with this regard. The importance of ER, as mentioned above and elaborated more in section 3, is discussed in the literature by Gouws (2002) and Gouws and Prinsloo (2005). This study adds the parameter of part of speech as the second factor which must have a key role in allocating different amounts of addressing to entries and specifically addresses the following questions:

(1) How does the AR in Hezaareh English-Persian dictionary correlate with the parameter of ER?

(2) How does the AR in Hezaareh English-Persian dictionary correlate with the parameter of part of speech?

(3) What are the implications of the study?

Before elaborating on the method section of the study, it seems necessary to discuss the notion of ER. 


\section{EQUIVALENT RELATIONS IN BILINGUAL DICTIONARIES}

The translation equivalents entered in a bilingual dictionary are regarded as "the most salient data category" (Gou ws 2002). A translation equivalent is a TL item, which can be used to substitute the SL item in a specific occurrence, depending on specific contextual and cotextual restrictions. According to Gouws, the relation between SL ite ms and TL items is known as an equivalent relation (ER) which can be of three different types: congruence, divergence and surrogate equivalence. In fact, the distinction between full equivalence, partial equivalence and zero equivalence motivates the existence of the ERs.

\section{A. Congruence}

An ER of congruence, which is also known as "full equivalence" (Gouws and Prinsloo, 2005, p.154) is characterized by a one-to-one relation on lexical, prag matic and semantic level. As a result, both SL and TL forms have exactly the same meaning and implication. For a lexicographer, this type of ER holds few problems since "it implies that the translation equivalent can substitute the lemma in all its uses" (Gouws 2002, p.196). However, the existence of congruence is limited to very rare cases. The entry for the le mma ambulance chosen from Hezaareh can be regarded as an example of congruence:

(1) ambulance ...

(Haghshenas et al. 2003, p.40)

In this example the SW has one meaning in English for which only one translation equivalent is offered in Persian.

\section{B. Divergence}

Divergence is the most typical ER in bilingual dictionaries. It is characterized by a one to more that one relation between SL and TL forms. To put it in other words, in cases where more than one translation equivalent exists for a given lemma, the equivalent relation is that of divergence. Divergence might happen on lexical grounds, semantic grounds or both.

Lexical divergence prevails where a monosemous lemma has more than one translation equivalent and the translation equivalents are mostly partial synonyms in the TL. Most of the dictionaries use a comma to separate these equivalents. In Hezaareh the English lemma patient as a noun, which can be regarded as a case of lexical divergence, is provided with two translation equivalents which are separated by a comma:

\section{(2) patient ...}

(Haghshenas et al. 2003, p. 1207)

On the semantic level there is a one to one relation between the SL and the TL. It means that بيمار/ and an / an synonomous. But on the lexical level there is a one to more than one relation, because for one SW two equivalents are proposed. As a result, there is a relation of divergence on the le xical level.

According to Gouws (2002, p.198), where lexical divergence prevails the lexicographer has to make sure whether the translation equivalents are full or partial synonyms. If they are full synonyms, which is very seldom the case, the lexicographic treatment can be similar to the case of congruence. But, more often than not the equivalents are synonymous only partially. In such cases, the user should not only be informed about the fact that these partial synonyms can substitute the source language word, but should also be cautioned that the TL equivalents cannot substitute one another in all contexts. Here meaning discrimination comes to the play. As a result, the lexicographer should make use of some sort of contextual clues to indicate the typical environment of the translation equivalents.

The second type of lexicographic divergence is semantic divergence. It happens where the SL lemma is a polysemous lexical item. Since cases of polysemy are language specific, and since the chances are minimal that a single TL item will have the same semantic load as the SL item, a translation equivalent needs to be introduced for each sense of the source language word. Dictionaries use different devices to mark the occurrence of semantic divergence. Some use a numbering system to differentiate between different sets of translation equivalents each representing one sense of the SL lemma in the TL, some others use semicolons as markers to separate translation equivalents representing different polysemous senses of the lemma.

Gouws (2002, p.199) believes that no lexicographer may assume that the users of the dictionary intuitively know which translation equivalent to choose from among a nu mber of them offered in the bilingual dictionary. Consequently, lexicographers are compelled to utilize additional strategies to give rise to an optimal retrieval of in formation on the part of the user. The following is an example of a polysemous SW, which has two meanings in Persian and for each meaning only one translation equivalent is offered in Hezaareh dictionary - a case of semantic divergence:

$$
\text { (3) news paper ... }
$$

a daily newspaper

(Haghshenas et al. 2003, p.1102)

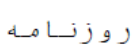

The word newspaper as a polysemous word is reported to have three different but related meanings according to LDCE3: 1. a set of large folded sheets of paper containing news, articles, pictures, advertisements etc printed and sold daily or weekly, 2. Sheets of paper from old newspapers, 3. A company that produces a newspaper. As evident, in Hezaareh dictionary two meanings are reported for the SW, each containing only one choice of translation equivalent. 
Numbers one and two in Persian are the translation equivalents of one and two in English, and no Persian translation equivalent is offered for nu mber three in English. In Hezaareh dictionary, one phrase is also given as an example for the first meaning of the SW.

It happens very often that both lexical and semantic divergence prevail in the translation equivalents offered for an $\mathrm{SL}$ item. To illuminate the point an example is given from Hezaareh:

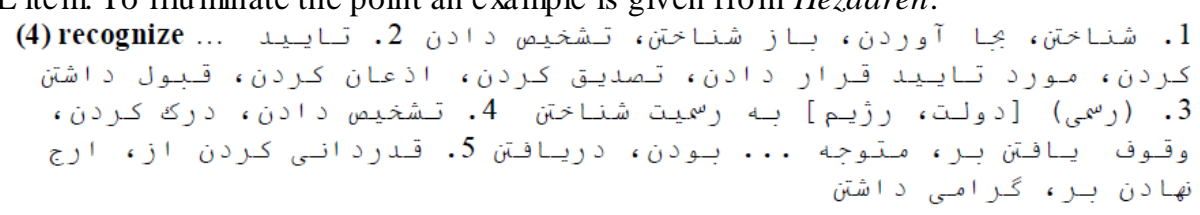

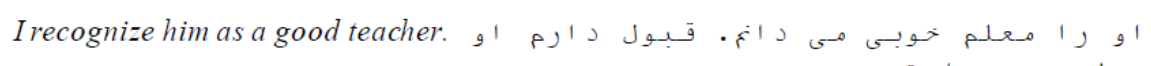

(Haghshenas et al. 2003, p. 1377)

Having a number of different but related meanings in English, recognize is regarded as a polysemous word. In Persian it has also five sets of translation equivalents. On the one hand, it has the requirements of being a case of semantic divergence and, on the other hand, each set of equivalents contains more than one translation equivalent. Such co-occurrence of lexical and semantic divergence gives rise to an ER of poly divergence which calls for a welldeveloped and consistently used system of conte xtual and cote xtual guidance.

\section{Surrogate Equivalence}

The existence of lexical gaps is very common in all languages. Where lexicographers are confronted with the lack of a TL lexical item which can be coordinated with a given SL item, a surrogate equivalent is created.

\section{METHODOLOGY}

To address the research questions, the researchers first chose the most frequently used general purpose, EnglishPersian dictionary as the dictionary for further investigations. Then, 500 lexical items were selected rando mly from the First Range vocabulary items. The sampled items included nouns, adjectives, verbs and adverbs. Afterward, AR for each category of ER and part of speech was calculated and considering the two parameters of the study, the effectiveness of such a treatment was discussed. Below is the detailed report of the procedure.

To choose the most frequently used general purpose English-Persian dictionary, the researchers asked 673 people about the English-Persian dictionary they used. As general purpose dictionaries were chosen for investigation, the researchers chose the participants from among those who are certain users of these dictionaries. That way, Hezaareh was chosen by 387 participants (i.e. more than $50 \%$ of the participants). Thus, it was decided that this dictionary be the object of this study.

Then, the researchers randomly selected 500 lexical items, all from among the first range vocabulary items. The frequency of occurrence of the first range lemmas implies that they are the core vocabulary used by native speakers in their oral and written production, and consequently the items with which non-native speakers who are exposed to that language in one way or another, are more likely to be faced. To ascertain which words are listed as the first range in English, the researchers made use of the advantage offered by LDOCE3 as to marking the 3,000 most frequent words in both spoken and written English. To decide about the number of the words in each group of nouns, verbs, adjectives and adverbs, the researchers used proportional random sampling and tried to find the proportion of each part of speech to the total of them in the dictionary under study. Finally, such approximate proportions were applied to the selected sample of 500 lexical items. This resulted in 255 nouns, 128 adjectives, 74 verbs, and finally 43 adverbs (see Appendices 2 to 5). Then, the researchers calculated the AR for each part of speech.

In order to investigate the effect of ER on AR, the ER for each word was determined; 78 words were found to have the ERs of either congruence or lexical divergence and 422 words had the ER of either semantic divergence or poly divergence (see Appendices 2 to 5). The reason why the four categories of ER elaborated above were reduced to two categories is that, as explained above, in the cases of lexical divergence the SW is monosemous and the only difference it has with the cases of congruence is that more than one translation equivalents are offered for the SW, but these equivalents are all synonymous. Taking the limitations imposed on print dictionaries into consideration, it is not log ical to expect dictionaries to provide examples or any other kind of addressing strategies for all such synonymous alternatives. As a result, the cases of lexical divergence and congruence were included in one category. As for the second category of this study - semantic or poly divergence - it can be argued that since in the cases of semantic and poly divergence the SWs are polysemous, the need for implementing more addressing strategies and helping the users discriminate the different meanings appropriately, is more pressing.

\section{RESULTS}

\section{A. The Effect of ER on AR}


To investigate whether Hezaareh treated ERs systematically with regard to the amount of addressing they received, first the AR of each category of ER was calcu lated.

TABLE 1

ERS ANDTHEIR AR

\begin{tabular}{|l|l|l|l|}
\hline ER & N & AR (Mean) & SD \\
\hline Congruence and Lexical divergence & 78 & 0.48 & 0.52 \\
\hline Semantic divergence and Poly divergence & 422 & 0.57 & 0.34 \\
\hline Total & 500 & 0.55 & ----- \\
\hline
\end{tabular}

As indicated in Table 1, the first column shows the ERs. In here, the ERs of congruence and lexical divergence which require less AR are included in one category, while semantic divergence and poly divergence are considered as the category requiring higher AR. The second and third columns represent the number of items and the AR of each category of ER, respectively. Finally, the last column shows the standard deviations. It is shown in Table 1 that the total ratio of the addressed meanings to all meanings is 0.55 . This implies that almost half of the Persian meanings offered in Hezaareh are left unaddressed. However, the cases of semantic and poly divergence receive more addressing (0.57) in comparison with ERs of congruence and lexical divergence (0.48).

To find out whether the difference in the amount of addressing received by different ERs is significant, an independent T-Test was run. The results on the data, however, did not show any statistically significant differences between the two groups $(\mathrm{t}(89.43)=-1.46, \mathrm{p}>.05))$.

\section{B. The Effect of Part of Speech on AR}

At this stage of analyzing the data, attempts were made to find out if there was any relation between part of speech and AR. The AR for each category was calculated. Table 2 presents the categories of part of speech, the number of words in each category and the AR of each category.

TABLE 2

CATEGORIES OF PART OF SPEECH ANDTHEIR AR

\begin{tabular}{|l|l|l|l|}
\hline Part of speech & N & AR (Mean) & SD \\
\hline Noun & 255 & 0.57 & 0.35 \\
\hline Adjective & 128 & 0.76 & 0.33 \\
\hline Verb & 74 & 0.31 & 0.24 \\
\hline Adverb & 43 & 0.26 & 0.39 \\
\hline Total & 500 & 0.55 & 0.37 \\
\hline
\end{tabular}

According to the table, adjectives received the highest AR (0.76). The second highest AR belongs to nouns (0.57), followed by verbs (0.31) and adverbs (0.26). The one-way ANOVA was conducted to explore if the relationship between the categories of part of speech and their ARs was meaningful. The test indicated that there was a significant difference between the amount of addressing different categories of part of speech received $(\mathrm{F}(3,496)=38.73, \mathrm{p}<.05))$.

\section{DISCUSSION}

The results of analyzing the data showed that there was no meaningful relationship between the type of ER and the amount of addressing each word received. This indicated that with regard to AR, Hezaareh does not distinguish between the items in which congruence or lexical divergence prevails, and the items which have the ER of either semantic or poly divergence. The question therefore is whether different ERs require different amounts of addressing. If yes, what is the rationale behind this difference? To address these questions and hence assess the performance of Hezaareh, it seems necessary to consider each ER from the perspective of the users.

As for the cases of congruence, as it was defined and exemplified earlier, there is only one translation equivalent for the SL item. Looking the matter from the users' perspective, one can conclude that the potential user will not face any difficulty choosing the appropriate equivalent, since there is only one equivalent available. Therefore, no pressing need is felt on the part of the user for a contextualized word.

The same explanation is partially true about the cases of lexical divergence, as in such cases there is only one sense for which a range of lexical items is offered; that is, there is only one set of translation equivalents in which some synonymous equivalents are offered. Here again, the user is faced with only one sense. The only thing she needs to do is to choose one of the items from among the synonymous equivalents offered. This does not seem to pose a serious problem to the user. Apparently, the users of Hezaareh dictionary are native Persian speakers who are masters of their own language. Therefore, when facing an English item which has only one sense, but more than one synonymous Persian translation equivalents, they can easily decide which one to choose. Besides, in many cases it might be possible to use some of the equivalents interchangeably. Therefore, here again the need for addressing is not so urgent.

One might claim that even in cases of congruence and lexical divergence examples and other methods of contextualizing and addressing are needed, because their function is not only to help users discriminate the senses of a word, but also they serve some other functions. For example, they might serve some grammatical functions indicating the morphological and syntactic behavior of the word and serve as models of correct usage (Toope, 1996). They might 
also fulfill collocational functions, enabling the user to examine lexical collocations in a larger context (Yong and Peng, 2007). Therefore, if examples are reduced from entries with ERs other than semantic or poly divergence, other functions of examples will be hampered.

In providing a reply to the above argument, it seems necessary to stress the fact that discussing the importance of paying attention to more demanding ERs, does not necessarily mean reducing the amount of addressing strategies employed for other ERs. Especially in the case of Hezaareh dictionary, as around half of the senses are left unaddressed it is not wise to reduce the existing examples or glosses from the entries. The implication the discussion might bear is that allocating meaning discriminatory strategies should be systematic and based on the users' needs analysis. It is obvious that in relation to words with more meanings, the users need more meaning discriminatory strategies. Besides, each dictionary is to serve a predetermined intended purpose. Hezaareh as a general purpose English-Persian dictionary is to serve decoding purposes; it is a dictionary for comprehension. Therefore, like any other decoding dictionary, the primary objective of the users who make reference to it is to find the translation equivalents of the SL items. The need for knowing about grammatical and morphological behavior of the word as well as its collocational behavior is felt mostly when the users are occupied with encoding purposes; that is, production related activities. That is why dictionaries are advised to implement exemplification policies in line with the nature of them and the look-up needs of their intended users $(\mathrm{Xu}, 2008)$. What adds to the overriding importance of establishing clear, conscious, and deliberate policies of exemplification and addressing is the fact that in print dictionaries such as Hezaareh, the problem of space is also a concern. Print dictionaries have limited space in comparison with software dictionaries, so they are advised to make the best use out the space available to them by implementing wise strategies (Yong and Peng, 2007).

Concerning the second research question, the results suggest that in Hezaareh there is a meaningful relationship between part of speech and the amount of addressing the word receives. In fact, Hezaareh tends to address nouns and adjectives more than verbs and adverbs. In decoding tasks, users often encounter comprehension related difficulties with a TL item. To implement a systematic strategy with regard to the addressing of items belonging to different categories of part of speech in a bilingual receptive dictionary, one should keep an eye on satisfying the decoding needs of the intended users.

It is believed that as the kernel of a sentence, a verb has an important role in comprehension (Xu, 2008). According to Béjoint (1981) the first choice of users for retrieval of information in dictionaries is always the verb. Although many users might not have a good command of function words, adverbs and adjectives, when it comes to decoding a statement in a foreign language they rarely look them up in a dictionary; instead, looking the verb up, they try to grasp the meaning of the whole statement (Xu, 2008). Their search for the meaning of adverbs and adjectives tends to be limited to the cases where such items have a pivotal role in understanding the whole utterance, or where the purpose of looking up is to find the meaning of a specific adverb or adjective. However, if a dictionary is particularly geared to satisfying the encoding needs of the users, the requirements would differ. In such a case, the user is obliged to know about the meaning of the ite $\mathrm{m}$, as well as its syntactic, morphological, and collocational behavior.

Further, verbs are believed to have more senses than other categories of part of speech (Miller and Fe llbaum, 1992; Brown, 1994; Källkvist, 1997; Xu, 2008; Elston-Güttler and Williams, 2008). According to Miller and Fellbau m (1992), in Collins English Dictionary verbs on the whole have an average of 2.11 senses while nouns have 1.74 senses. Along these lines, Brown (1994) confirmed the general tendency of verbs to be polysemous and their senses to be context dependent. Xu's sample als o confirmed the same claim in the Big Five (Xu, 2008).

Having this in mind, one can conclude that verbs are the category deserving more attention as far as addressing is concerned. This is however not the case in Hezaareh dictionary. Likewise the case of ERs, the discussion in terms of the importance of giving priority to verbs in devising addressing strategies in bilingual dictionaries, by no means intends to underestimate the importance of addressing strategies for other categories of part of speech. The point is that to have a more systematic approach to the issue of meaning discrimination and to avoid the fallacious practice of consistent or random addressing, some items should be prioritized depending on the type, purpose and perspective of the dictionary.

To sum up, what certainly calls the systematicity of Hezaareh into question with regard to its addressing policy is that two important, decisive parameters which should influence the amount of addressing the lemmas receive are overlooked: ER and part of speech.

\section{CONCLUSION}

This article examined if in Hezaareh English-Persian dictionary the two variables of ER and part of speech play any role in the ARof words. It was found that the type of ER does not influence the AR. Hezaareh does not distinguish between the items in which congruence or lexical divergence prevails, and the words having the ER of either semantic or poly divergence. As for the effect of part of speech on the AR, the study revealed that in Hezaareh there is a meaningful relation between the variable of part of speech and the amount of addressing the word receives. In fact, Hezaareh tends to address nouns and adjectives more than verbs and adverbs.

Assessing the practice of Hezaareh in allocating addressing strategies to the words, the study suggests some urgent considerations. In short, words having the ER of either semantic or poly divergence, due to their nature and the users' look-up needs, deserve more AR. Besides, the role verbs play in comprehension related purposes and their polysemous 
nature make them good candidates for receiving higher rates of addressing in a bilingual receptive dictionary. As a result, the two factors of ER and part of speech are advised to be taken into consideration and respected while ass igning addressing strategies to items .

As a concluding remark, it should be added that dictionary making and compilation is, no doubt, a painstaking activity which requires great a mount of expertise, skill, energy, time, and effort, and no dictionary assessment can deny the overall value of the dictionary under study, since each assessment is limited to only one aspect of the dictionary out of the thousands. The purpose of this study was therefore by no means to depreciate the value of the great job done by the lexicographers of Hezaareh. Hezaareh is the only English-Persian dictionary in which some signs of a systematic project are claimed to be observable (Emami, 2001). This study is conducted simply to give rise to a more objective assessment which according to Qaneeifard (2003) is believed to be a major step toward improving the present state of English-Persian bilingual le xicography.

\section{APPENDIX 1: LIST OF ABBREVIATIONS}

AR: addressing rate

ER: equivalent relation

LDOCE3: Long man Dictionary of Contemporary English, Third Ed ition

OALD6: Oxford Advanced Learners' Dictionary, Sixth Edition

SL: source language

SW: source word

TL: target language

TW: target word

APPENDIX 2: SAMPLED NOUNS AND THEIR ER

\begin{tabular}{|c|c|c|}
\hline $\begin{array}{l}\text { Equivalent } \\
\text { relation }\end{array}$ & Sampleditems & Total \\
\hline Congruence & afternoon, album, ambulance, ashtray, chemical, cigarette, golf, piano, pie & 9 \\
\hline $\begin{array}{l}\text { Lexical } \\
\text { divergence }\end{array}$ & $\begin{array}{l}\text { ability, agricult ure, ally, alternative, anger, chat, classroom, district, dustbin, electricity, evaluation, excuse, } \\
\text { fortnight, fragments, hobby, mirror, outcome, patient, pension, raffle, reputation, unemployment, valor, zone }\end{array}$ & 24 \\
\hline $\begin{array}{l}\text { Semantic } \\
\text { di vergence }\end{array}$ & alcohol, arch, newspaper & 3 \\
\hline $\begin{array}{l}\text { Poly } \\
\text { di vergence }\end{array}$ & $\begin{array}{l}\text { accident, account, acid, act, address, adult, advantage, affair, age, agreement, aid, aim, air, alarm, alliance, } \\
\text { allowance, amount, angle, anxiety, apology, appeal, appearance, application, approach, area, argument, arm, army, } \\
\text { arrival, article, aspect, assault, assembly, asset, assignment, assumption, att it ude, audience, baby, background, ball, } \\
\text { barrel, beauty, bed, bill, book, boy, bridge, buyer, cabinet, calculation, call, campaign, cancer, candidate, cap, } \\
\text { carriage, cartoon, cast, cause, ceiling, certificate, chair, chance, column, command, company, cross, determination, } \\
\text { diet, dinner, division, draft, drive, drop, duty, ear, escape, fabric, fence, fire, force, form, foundation, game, gear, } \\
\text { girl, goal, governor, grass, guidance, gulf, gun, handle, hearing, hero, holder, implication, infection, influence, } \\
\text { intention, interest, interval, investment, island, item, jacket, journey, king, label, ladder, land, landlord, law, layer, } \\
\text { leaf, lecture, library, link, log, lottery, lump, magazine, major, manner, margin, mate, measure, metal, migrat ion, } \\
\text { model, moment, motion, net, note, notion, nut, objective, odds, offence, opponent, option, order, outfit, pace, pack, } \\
\text { panel, parent, passenger, peace, personnel, phenomenon, philosophy, pilot, pipe, plane, player, poetry, pound, } \\
\text { presentation, president, prince, progress, proportion, prospect, provision, publicity, pudding, qualificat ion, quant ity, } \\
\text { queen, range, reaction, reader, recession, recovery, regulation, religion, reservation, respect, resignation, reward, } \\
\text { rout ine, sample, sand, scheme, shaft, show, sight, } \\
\text { significance, sister, solution, space, spirit, staff, st one, stuff, subject, table, tail, tap, tea, test, toilet, track, } \\
\text { transaction, trustee, union, unity, use, vacancy, version, view, virt ue, wall, wave, woman, wood, yard }\end{array}$ & 219 \\
\hline
\end{tabular}

APPENDIX 3: SAMPLED ADJECTIVES AND THEIR ER

\begin{tabular}{|c|c|c|}
\hline $\begin{array}{l}\text { Equivalent } \\
\text { relation }\end{array}$ & Sampleditems & Total \\
\hline Congruence & alone & 1 \\
\hline $\begin{array}{l}\text { Lexical } \\
\text { di vergence }\end{array}$ & $\begin{array}{l}\text { actual, additional, advanced, afraid, amazing, approximate, aware, collective, comprehensive, considerable, } \\
\text { damn, detailed, early, equivalent, gray, international, joint, maximum, permanent, pleased, powerful, rural, tall, } \\
\text { welcome }\end{array}$ & 24 \\
\hline $\begin{array}{l}\text { Semantic } \\
\text { divergence }\end{array}$ & 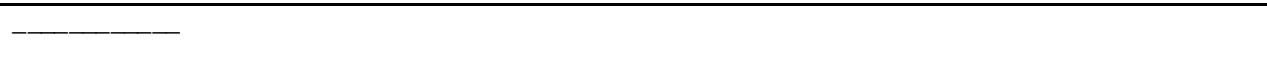 & -- \\
\hline $\begin{array}{l}\text { Poly } \\
\text { di vergence }\end{array}$ & $\begin{array}{l}\text { active, adult, aged, aggressive, apparent, aut omatic, available, awkward, basic, bitter, black, blank, blind, blue, } \\
\text { brave, brief, broad, broken, busy, calm, civil, clear, clinical, cold, common, commercial, complete, complex, } \\
\text { concerned, concrete, crucial, curious, dark, decent, direct, domestic, dry, dull, dumb, easy, economic, fair, false, } \\
\text { fine, firm, formal, fresh, genuine, global, grand, green, handy, healthy, immediate, keen, level, liberal, live, } \\
\text { lonely, loose, lower, mad, marked, material, mental, modern, neat, official, oppressive, out st anding, particular, } \\
\text { pink, plain, poor, popular, positive, practical, private, pure, quick, radical, raw, recent, red, remote, rough, royal, } \\
\text { set, silent, smooth, soft, sophisticated, steep, strange, substantial, thick, tight, total, tremendous, tricky, ultimate, } \\
\text { underlying, wide }\end{array}$ & 103 \\
\hline
\end{tabular}


APPENDIX 4: SAMPLED VERBS AND THEIR ER

\begin{tabular}{|l|l|l|}
\hline $\begin{array}{l}\text { Equivalent } \\
\text { relation }\end{array}$ & Sampleditems & Total \\
\hline Congruence & acquire, apologize, blame, predict, prevent, remark & 6 \\
\hline $\begin{array}{l}\text { Lexical } \\
\text { di ve rgence }\end{array}$ & - & $\begin{array}{l}\text { Semantic } \\
\text { di ve rgence }\end{array}$ \\
\hline $\begin{array}{l}\text { Poly } \\
\text { di ve rgence }\end{array}$ & $\begin{array}{l}\text { accept, act, add, admit, advise, affect, alter, amend, anticipate, appeal, apply, appoint, appreciate, approach, argue, } \\
\text { illustrate, impress, involve, just ify, lick, locate, maintain, negotiate, obtain, pause, perceive, persuade, pray, } \\
\text { prepare, presume, quote, realize, recall, reckon, recognize, repeat, represent, retain, reveal, satisfy, share, spend, } \\
\text { suspect, swallow, sweep, tend, threaten, transfer, treat, undertake, visit, whisper, withdraw }\end{array}$ & 68 \\
\hline
\end{tabular}

APPENDIX 5: SAMPLED ADVERBS AND THEIR ER

\begin{tabular}{|c|c|c|}
\hline $\begin{array}{l}\text { Equivalent } \\
\text { relation }\end{array}$ & Sampleditems & Total \\
\hline Congruence & respectively & 1 \\
\hline $\begin{array}{l}\text { Lexical } \\
\text { di ve rgence }\end{array}$ & basically, considerably, early, event ually, merely, moreover, of course, presumably, rarely, totally, way, whereby & 13 \\
\hline $\begin{array}{l}\text { Semantic } \\
\text { di ve rgence }\end{array}$ & $-\square-1-$ & -- \\
\hline $\begin{array}{l}\text { Poly } \\
\text { di vergence }\end{array}$ & $\begin{array}{l}\text { act ually, almost, altogether, badly, briefly, certainly, commonly, directly, down, fairly, further, generally, } \\
\text { honest ly, incident ally, indeed, literally, nat urally, normally, once, otherwise, particularly, perfectly, properly, } \\
\text { reasonably, sharply, shortly, somehow, technically, yet }\end{array}$ & 29 \\
\hline
\end{tabular}

\section{REFERENCES}

[1] Al-Kasimi, A. (1983). Linguistics and bilingual dictionaries. Leiden: E.J. Brill.

[2] Béjoint, H. (1981). The Foreign students use of monolingual English dictionaries: A study of language needs and reference skills. Applied Linguistics 3.2:207-22.

[3] Brown, G. (1994). The role of nominal and verbal expressions in retelling narratives: Implications for discourse representations. Working Papers in English and Applied Linguistics 1:81-90.

[4] Bullon, S. (1995). Longman dictionary of contemporary English. The living dictionary. London: British Library.

[5] Elston-Güttler, K. and Williams, J. (2008). First language polysemy affects second language interpretation: Evidence for activation of first language concepts during second language reading. Second Language Research 24.2:167-87.

[6] Emami, K. (2001). A closer look at Hezaareh English-Persian dictionary. Translator 34:63-70.

[7] Gouws, R. (2002). Equivalent relations, context and cotext in bilingual dictionaries. Journal of Linguistics 28:195-209.

[8] Gouws, R. and Prinsloo, D. (2005). Principles and practice of South Africa lexicography. Stellenbosch: SUN Press.

[9] Haghshenas, A. M. Samei, H. and Entekhabi, N. (2003). One volume Millennium English-Persian dictionary. Tehran: Farhang Moaser Publishers (Hezaareh)

[10] Källkvist, M. (1997). Lexical form-class effects in foreign language learning: A study of the English produced by advanced Swedish learners. Doctoral dissertation, University of Cambridge.

[11] Mafela, M. J. (2004). Bilingual dictionary and meaning discrimination in Venda. Euralex 2004 Proceedings: 501-509.

[12] Mafela, M. J. (2005). Meaning discrimination in bilingual Venda dictionaries. Lexikos 15:276-285.

[13] Mavoungou, P. A. (2001). Macro and microstructural issues in Mazuna lexicography. Lexikos 11:122-32.

[14] Miller, G. and Fellbaum, C. (1992). Semantic network of English. Cognition 41:197- 229.

[15] Mpofu, N. (2001). Problems of equivalence in Shona-English bilingual dictionaries. Lexikos 11:242-51.

[16] Piotrowski, T. (1994). Problems in bilingual lexico graphy. Wroclaw: University of Wroclaw.

[17] Qaneeifard, E. (2003). The challenges for lexicography in Iran. Translation Studies 1.1:31-42.

[18] Summers, D. (2001). Longman dictionary of contemporary English. $3^{\text {rd }}$ ed. London: Pearson Education Ltd. (LDOCE3)

[19] Svensén, B. (1993). Practical lexicography: Principles and methods of dictionary-making. Oxford: Oxford University Press.

[20] Toope, M. (1996). Examples in the bilingual dictionary. School of Translation and Interpretation, Ottawa: University of Ottawa.

[21] Wehmeier, S. (2000). Oxford advanced learner's dictionaries of current English. $6^{\text {th }}$ ed. Oxford: Oxford University Press. (OALD6)

[22] Xu, H. (2008). Exemplification policy in English learner's dictionaries. International Journal of Lexicography 21.4:395-420.

[23] Yong, H. and Peng, J. (2007). Bilingual lexicography from a communicative perspective. Amsterdam: John Benjamin Publishing Company.

Zohreh Gharaei received her B.A. and M.A. in Translation Studies from the University of Isfahan, Isfahan, Iran. She teaches translation related courses at institutes of higher education in Isfahan, Iran. Her areas of interest in research include theoretical and practical aspects of Translation Studies, especially literary translation, and English-Persian bilingual lexicography. Her recent publications include "Free Indirect Discourse in Farsi Translations of Mrs. Dalloway", CLCWeb: Comparative Literature and 
Culture (2012), and "The Pragmatics of English-Persian Dictionaries: Problems and Solutions", International Journal of English Linguistics (2011).

Ahmad Moinzadeh holds a Ph.D. in linguistics from the University of Ottawa. He is assistant professor of Applied Lingu istics at the University of Isfahan, Faculty of Foreign Languages, Department of English. Dr. Moinzadeh has taught in this department for about fifteen years. He has supervised five Ph.D. dissertations and more than 35 M.A. theses.

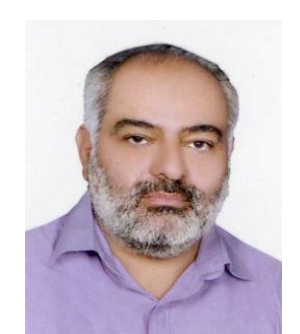

Hossein Barati works in the English department, University of Isfahan, where he is assistant Professor of Applied Linguistics. He has a PhD in 'Language Testing' from University of Bristol and has been involved in research in language testing, programme evaluation, reading strategies, and classroom discourse. Before becoming a university lecturer in 1992, he worked as a language teacher at Ministry of Education, Isfahan, Iran. He has published in areas of language testing and assessment, and language programme evaluation. $\mathrm{He}$ is a member of a research project on Developing a new model of teaching to adult English non-majors at University of Isfahan, funded by University of Isfahan.

He has also co-authored some publications on DIF in Iranian National University Entrance Exam (INUEE), 2007; Linguistic constraints and language teaching, 2008; and Cultural differences in EFL performance on cloze tests, 2010. Further a text-book A step forward in English for intermediate EFL learners is among his latest publications.

Dr. Barati is currently working on 'New plans for Teaching English to Iranian adult non-majors', 'Teaching English to Iranian young learners, and 'The consequential validity of high stakes tests in the Iranian context'. 